\title{
What is the purpose of Physical Education for its functions? A reflection from the degree course of Pedagogy and Psychology
}

\author{
Antonio Díaz-Torriente \\ Department of Physical Education and Sports. Central University "Marta Abreu” de las Villas carretera \\ a Camajuaní, Km 12, Santa Clara. Villa Clara. Cuba.
}

\begin{abstract}
Physical education as a subject does not have an integration with the rest of the disciplines for university students. The development of management skills in students of Pedagogy and Psychology is among its most important objectives regarding physical education. The development of actions aimed at students. All this, taking into account their needs, also provides a series of actions aimed at preparing students and is supported by a system of principles, categories and concepts related to education sciences.

To the best of our knowledge there are not previous reports in this area. Actions related to the development of management skills in physical education have not been proposed through the needs and demands of the professional model in previous studies.
\end{abstract}

Key words: physical education, management skills, professional training, pedagogy, psychology

\section{Introduction}

The relation between physical education with many different categories is a fact, nevertheless, in this particular case, only the relation between physical education and the field of education will be considered. Sciences like Pedagogy and Psychology have dealt with several topics about the relation between physical education and general education, both in institutional and social recognition and in the real fact of how tempting it is for researchers to prove if Physical Education really contributes to these and other topics that we will not deal with in this article.

Both, Physical Education and physical activity are social phenomena due to their common nature and goals which have erected in highly recognized institutions, which turns them into the process of socialization.

Managing abilities are essential for any professional, but more for Psychology and Pedagogy teachers because their main role is managing the processes; these abilities are formed, in our opinion, from the pedagogical principles that manage the pedagogical process. Based on those elements, the main goal of this article is to characterize the professional abilities in the process of initial formation of the professionals in the fields of Pedagogy and Psychology. In our opinion, the skills can be classified as following: 


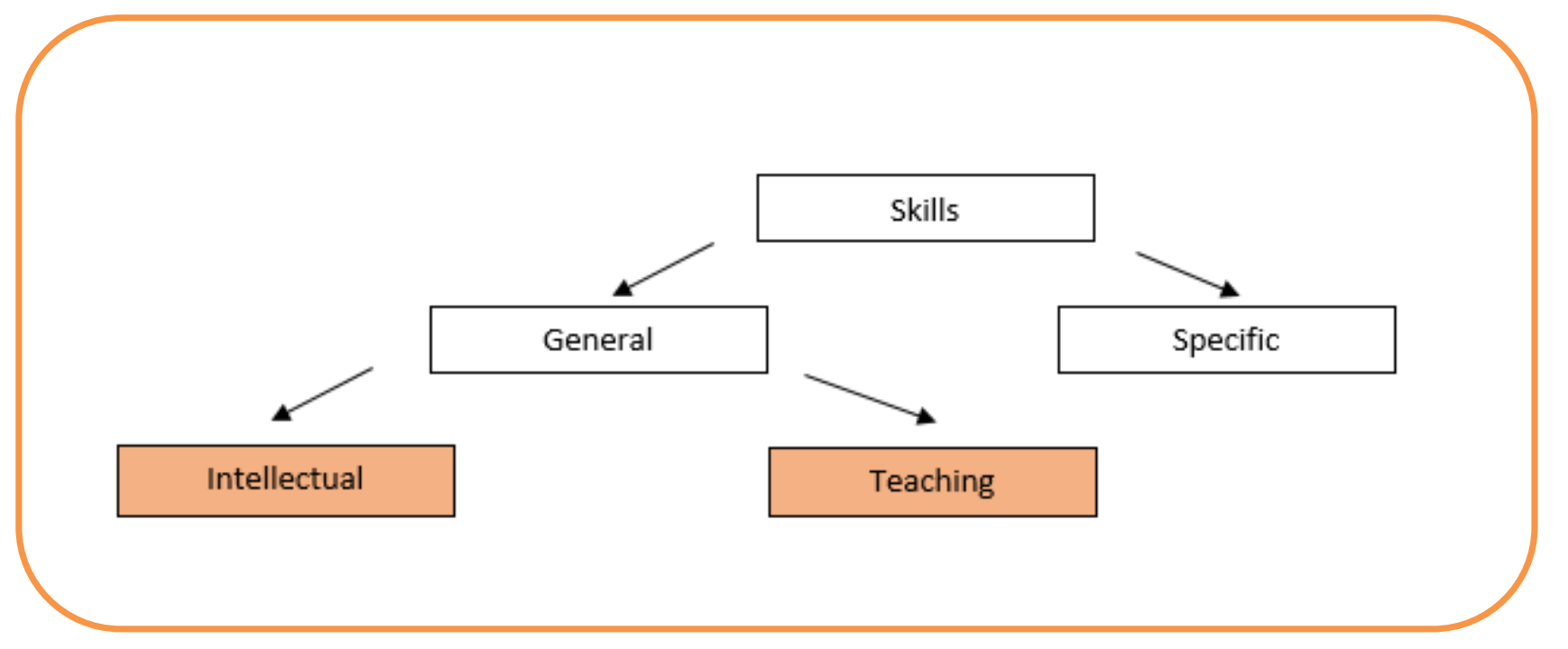

\section{Results and Discussion}

For a good performance of a professional in the field of Pedagogy and Psychology, all the above is based on the resizing of the use of physical activity. Mainly because he must be prepared to manage and guide the pedagogical process of training other professionals in the field of education with an emphasis on the development of professional skills.

Professional performance aimed at the management of the teaching and learning process should be aimed at the development of professional interests that guarantee the good quality of their professional development. Additionally, the development of professional knowledge and skills, to efficiently solve the problems of their pedagogical practice and the achievement of the independence and flexibility acquired in their professional behaviors. As well as a thoughtful thought that allows the orientation and originality in the solution of professional problems.

Previous research affirms that in order to achieve professional behavior in the pedagogical activity and develop their skills, it is essential to work systematically in the professional education of the student's personality.

This implies managing the system of educational influences on the basis of:

\# Professional approach to the teaching and learning process.

Recognize the active role of the student as the main subject of their professional training.

The pedagogical staff of each academic year is the main level in the professional education of the student's personality.

\section{Conclusion}

The discipline Physical Education allows the professional of Pedagogy and Psychology to use its contents in the solution of problems of their professional practice and the accomplishment of their functions, because it allows the planning of activities that favor socialization as it deals with situations inherent to the development of the student's personality.

\section{References}

Chin-Wen, C. Pre-service English Teachers' professional identity Construction through lesson Design and Delivery of English Remedial Education (2016) 
MOL2NET, 2019, 5, ISSN: 2624-5078

http://sciforum.net/conference/mol2net-05

Addine, F. Principles for the direction of the pedagogical process. In Compendium of Pedagogy. (2002). Havana: Education People (Ed).

Batista, G. The training of education professionals. (2009)

Cross R., Gearon, M. The confluence of doing, thinking, and knowing: Classroom practice as the crucible of foreign language teacher identity. In Dimensions of professional learning: Professionalism, identities and practice (2007) 53-68. Rotterdam: Sense Publisher (Ed). 